\title{
Diagnosis and molecular characterization of Anaplasma platys in dog patients in Yogyakarta area, Indonesia
}

\author{
Muh. Disna Faizal ${ }^{1}$, Aris Haryanto ${ }^{2}$, and Ida Tjahajati ${ }^{3, *}$ \\ ${ }^{1}$ Veterinary Science Study Program, Faculty of Veterinary Medicine, Universitas Gadjah Mada, Jalan Fauna 2 Karangmalang, Yogyakarta \\ 55281, Indonesia \\ ${ }^{2}$ Department of Biochemistry and Molecular Biology, Faculty of Veterinary Medicine, Universitas Gadjah Mada, Jalan Fauna 2 \\ Karangmalang, Yogyakarta 55281, Indonesia \\ ${ }^{3}$ Department of Internal Medicine, Faculty of Veterinary Medicine, Universitas Gadjah Mada, Jalan Fauna 2 Karangmalang, Yogyakarta \\ 55281, Indonesia \\ *Corresponding author: ida_tjahajati@ugm.ac.id
}

SUBMITTED 17 January 2019 REVISED 23 April 2019 ACCEPTED 14 June 2019

\begin{abstract}
Anaplasma platys is a tick-borne, Gram-negative bacterium that causes anaplasmosis, a companion vector-borne disease impacting dogs. Information on this disease remains limited in Indonesia. Its symptoms are not specific, so molecular analysis is required for a rapid and accurate diagnosis. GroEL is an essential gene commonly used for classification and species identification of many groups of bacteria, including Anaplasma spp. In this study, a molecular diagnosis of anaplasmosis based on the groEL gene sequence was conducted using PCR. In addition, the genetic diversity of Anaplasma platys in infected dogs was determined. Blood samples were collected from 51 dogs suspected of anaplasmosis from Prof. Dr. Soeparwi Animal Hospital, animal clinics, and pet shops in the Yogyakarta area, Indonesia, based on anamnesis, histories of tick infestations, and clinical symptom examinations. DNA extraction and PCR targeting the groEL gene were performed, followed by sequencing. Phylogenetic tree analysis and construction were carried out using the BLAST and MEGA programs. Positive PCR sample results (amplicon length of $624 \mathrm{bp}$ ) were found in 6 of 51 dogs. Samples A1 (KHJ/C2), A2 (KHJ/A2), A3 (KSK/L), A4 (KHJ/L), and A5 (KNP/M2) had close ties to Anaplasma platys (AF478129.1) from GenBank. Phylogenetic analysis showed a very high homology value (100\%) and bootstrap value of $100 \%$. It can be concluded that there was no genetic diversity in the Anaplasma platys found in infected dogs in the Yogyakarta area.
\end{abstract}

KEYWORDS Anaplasma platys; companion vector-borne disease (CVBD); groEL gene; phylogenetic analysis; polymerase chain reaction (PCR)

\section{Introduction}

Anaplasmosis in dogs is caused by the infection of Anaplasma phagocytophilum and Anaplasma platys (Sykes and Foley 2013). Anaplasma platys, which was previously known as Ehrlichia platys, is reported to cause canine cyclic thrombocytopenia in warm, tropical regions, such as the Mediterranean, Asia, Middle East, Africa, and Australia. The presence of Anaplasma in platelets is characterized by the presence of round, oval or peanut-shaped blue inclusion cells that have diameters ranging from 0.35 to $1.25 \mu \mathrm{m}$ (Lillini et al. 2006; Carrade et al. 2009). Anaplasma platys is transmitted by the brown dog tick (Rhipicephalus sanguineus) and Dermacentor spp. tick. Co-infection can occur together with other pathogenic agents transmitted by the same or other tick species. Thus, it will affect the clinical manifestations of diseases (Sykes and Foley 2013). According to Arraga-Alvarado et al. (2014), like other Anaplasma species, A. platys is zoonotic and therefore can infect humans.
The clinical symptoms of $A$. platys infection in dogs have been described both experimentally in the laboratory and naturally in the field by researchers from Greece (Kontos et al. 1991), France (Beaufils et al. 2002), and Israel (Harrus et al. 1997). The symptoms are high fever, lethargy, anorexia, weight loss, pale mucous membranes, petechiae, nasal discharge, and lymphadenomegaly (Santos et al. 2009; Dyachenko et al. 2012). The incubation period of $A$. platys infection in dogs lasts for 1-2 weeks. The incubation period will continue to thrombocytopenia and fever, which appear and disappear cyclically every 12 weeks (Gaunt et al. 1990).

The diagnosis of anaplasmosis depends on detecting the presence or exposure of an infectious agent (de Farias Rotondano et al. 2012). Blood smear examination has a low sensitivity because the stage of morulae $A$. platys can only be detected in the initial phase of infection (Otranto et al. 2010). Serological tests such as indirect immunofluorescence are commonly used, but this examination sometimes interferes with cross-reaction of antibodies 
between Anaplasma species (Beaufils et al. 2002; Greene 2012). The polymerase chain reaction (PCR) method can make it possible to detect anaplasmosis active infections, because this method can directly amplify the presence of A. platys based on 16S rRNA, groEL, or msp2 gene targets (Fuente et al. 2006; Matei et al. 2016; Vargas-Hernandez et al. 2016; Lee et al. 2017; Ribeiro et al. 2017). GroEL protein is a part of the heat shock protein-group (HSP) (Yu et al. 2001). Heat shock proteins are regulated in physiological stressful situations, for example during an increase in temperature or toxicity, therefore this protein serves as a cell protection tool (Dasch et al. 1990). The sequence of genes is considered a useful tool for phylogenetic analysis of Anaplasma spp. (Dasch et al. 1990; Jahfari et al. 2014). The 'blind spot' in some genera makes the $16 \mathrm{~S}$ gene not discriminatory enough to identify certain species (highly conservative), so that the groEL gene can support and expand phylogenetic results (Dasch et al. 1990; Jahfari et al. 2014). The PCR method can also be used to detect specific gene fragments after the amplification process. The sequencing process of PCR results can identify specific infecting species of Anaplasma spp.(Ybañez et al. 2012, 2016; Bonilla et al. 2017).

Anaplasmosis is an important zoonotic disease. Opportunistic infections can occur in humans and dogs, which will aggravate the patient's condition until death (Sykes and Foley 2013). Difficulties in diagnosing this disease also need to be considered, because it can cause significant economic losses due to the administration of drugs that are less precise and continuous. Studies on the diagnosis of anaplasmosis in dogs in Indonesia have not been widely carried out. Limited research by Hadi et al. (2016), on the prevalence of anaplasmosis in dogs, has been reported in several cities, namely Bogor, Jakarta, and Bandung. However, the specific species of Anaplasma spp. which infects the dogs was not specifically identified. The aim of this study was to conduct a molecular diagnosis of anaplasmosis based on the groEL gene sequence using the PCR method. In addition, this study was also intended to study the genetic diversity of $A$. platys species in infected dog patients from the Yogyakarta area, Java, Indonesia. This study is expected to be beneficial as a standard reference in diagnosing anaplasmosis in dogs more accurately in order to control the spread of anaplasmosis in Indonesia.

\section{Materials and methods}

\subsection{Sample}

This study was conducted in March-November 2018. It was approved by the Ethical Committee of the Faculty of Veterinary Medicine, Universitas Gadjah Mada, Yo- gyakarta, Indonesia, No: 034/EC-FKH/Int./2018 (issued on November 27, 2018). Blood samples were collected from 51 dogs with clinical symptoms and were suspected to have been infected by $A$. platys. The dog patients showed symptoms such as fever, weakness, and haemorrhage. The supporting data were that the dogs were also infected by ticks, or previously reported to have a history of tick infection. The blood samples were collected from dog patients in Prof. Dr. Soeparwi Animal Hospital Faculty of Veterinary Medicine Universitas Gajah Mada, several animal clinics, and pet shops in the Yogyakarta area.

\subsection{Anamnesis and physical examination}

Anamnesis was done by interviewing the animal owners or nurses to obtain detailed information regarding the history of previous diseases suffered by the dog patients which were related to tick infection. Physical examination was carried out starting from an examination of body temperature, state of mucous or conjunctival membranes, the examination of hair condition (hair loss/presence of ticks), and observation of behavior (weakness/lethargy) (Kelly 1984; Beaufils et al. 2002).

\subsection{Blood sample collection}

Blood samples were taken through antebrachii cephalica veins as much as $0.5-2.5 \mathrm{~mL}$ using a $1 \mathrm{~mL}$ syringe (One Med, Indonesia) for small dog breeds and $3 \mathrm{~mL}$ syringe (One Med, Indonesia) for large dog breeds. Blood samples were collected into Vaculab tubes (One Med, Indonesia) with EDTA K3 as an anticoagulant (Beaufils et al. 2002), and then were stored at $4^{\circ} \mathrm{C}$, tightly closed, and protected from light.

\subsection{DNA isolation}

Two hundred microliters of blood samples from dog patients were extracted using gSYNC DNA Extraction Kit (Geneaid Biotech Ltd., Taiwan). The procedure for DNA extraction from the blood was carried out according to the standard method recommended by the manufacturer.

\subsection{DNA amplification}

Amplification of isolated DNA from the blood was carried out using pairs of forward and reverse primers with the groEL target gene (Table 1). DNA amplification using KAPA Taq PCR Kits (Kapa Biosystems, South Africa) was done by mixing into the microtube as much as 6.5 $\mu \mathrm{L} \mathrm{H}_{2} \mathrm{O}, 1 \mu \mathrm{L}$ forward primer, $1 \mu \mathrm{L}$ reverse primer, $4 \mu \mathrm{L}$ DNA, and $12 \mu \mathrm{L}$ KAPA Taq PCR Kits (Kapa Biosystems, South Africa) so that the final volume was $25 \mu \mathrm{L}$. All of these components were mixed until the mixture was ho-

TABLE 1 The sequence of primer nucleotide sequences amplifying the groEL gene (Alberti et al. 2005).

\begin{tabular}{llll}
\hline Target gene & Primer & Nucleotide sequence & Length of amplicon (bp) \\
\hline \multirow{2}{*}{ groEL } & EphplgroEL-F & ATGGTATGCAGTTTGATCGC & 624 \\
& EphplgroEL-R & TCTACTCTGTCTTTGCGTTC & \\
\hline
\end{tabular}


mogeneous. The microtube then was inserted into Thermal Cycler (GTC96S, Cleaver Scientific Ltd., UK) under the following conditions: initial denaturation at $94^{\circ} \mathrm{C}$ for $5 \mathrm{~min}$, followed by denaturation at $94^{\circ} \mathrm{C}$ for $45 \mathrm{~s}$, annealing at $56^{\circ} \mathrm{C}$ for $45 \mathrm{~s}$, and extension at $72^{\circ} \mathrm{C}$ for $60 \mathrm{~s}$. This process was carried out repeatedly for 40 cycles, followed by the final extension at $72^{\circ} \mathrm{C}$ for 10 min and ended with a final hold at $4^{\circ} \mathrm{C}$.

\subsection{DNA electrophoresis}

The DNA electrophoresis started by the preparation of $1.5 \%$ agarose gel $(0.75 \mathrm{~g}$ agarose in $50 \mathrm{~mL}$ Tri Borate EDTA / TBE buffer 1x). DNA samples of $5 \mu \mathrm{L}$ and DNAloading dye (Geneaid Biotech Ltd., Taiwan) of $2 \mu \mathrm{L}$ were loaded into the gel well. DNA ladder 100 bp markers (Geneaid Biotech Ltd., Taiwan) were included in the last well as much as $5 \mu \mathrm{L}$. Electrophoresis was carried out for 30-45 min with 100 volts. The gel was then visualized on a UV transilluminator. Analysis of amplification products was done based on the fragment size compared to the band position in the marker.

\section{7. $P C R$ product purification}

Purification of PCR products was performed in PT Genetika Science, Jakarta, Indonesia, based on the standard protocol of the manufacturer.

\subsection{Phylogenetic analysis}

PCR products were sequenced at PT. Genetika Science, Jakarta. Then, the result of Anaplasma spp. groEL gene sequencing was analyzed using the Basic Local Alignment Search Tool (BLAST). The sequencing results of all samples were compared with groEL sequences of Anaplasma spp. obtained from GenBank using the Clustal W Algorithm multiple alignments methods. Phylogenetic trees were constructed based on the Neighbor-Joining method using Molecular Evolutionary Genetics Analysis (MEGA) software version 7.0. The analysis process was carried out by bootstrapping 1,000 times repetition; identification of genetic distance and the presence of nucleotide substitutions were analyzed according to the parameters of the Kimura-2 model.

\section{Results}

\subsection{DNA from dog blood samples were positive for groEL}

The electrophoresis results from 6 dog samples showed the formation of DNA bands from PCR amplification which was parallel to the positive control at 624 bp (Figure 1). This shows that the primer attached to the groEL gene target which corresponded to the amplification length. The PCR results showed that the dog DNA samples studied were positive for Anaplasma spp. molecularly (Alberti et al. 2005; Bonilla et al. 2017). The PCR products of 51 dogs can be seen in Table 2 .

Five positive samples of unpurified PCR products (KHJ/C2, KHJ/A2, KSK/L, KHJ/L, and KNP/M2) were sequenced at PT. Genetika Science, Jakarta, Indonesia. Purification was carried out prior to the process of sequencing the PCR products. The electrophoresis result of the purified PCR products can be seen in Figure 2.

\subsection{BLAST analysis}

The sequencing results of the (purified) PCR products from five positive samples infected with Anaplasma spp. were analyzed using the online Basic Local Alignment Search Tool (BLAST) on the National Center for Biotechnology Information (NCBI) website (https://blast.ncbi.nlm.nih .gov/Blast.cgi). The parameters observed included max score, total score, query coverage, identity, and E-value (Expectation value). Max score is the highest value between the query and the total segment in the database. The max score is generally the same as the total score. Query coverage is the percentage value of the total nucleotide length of the sample that is good enough to be aligned with the nucleotide sequence found in GenBank. Identity indicates the percentage similarity of the nucleotide sequences of samples that are aligned with the nucleotide sequence in GenBank. A higher value of the four parameters shows more similar sequence between query and database. E-value is the level of probability that the similarity between sequence pairs is the result of random events; lower E-value indicates more significant similarity with database sequence (Aprilyanto and Sembiring 2016).

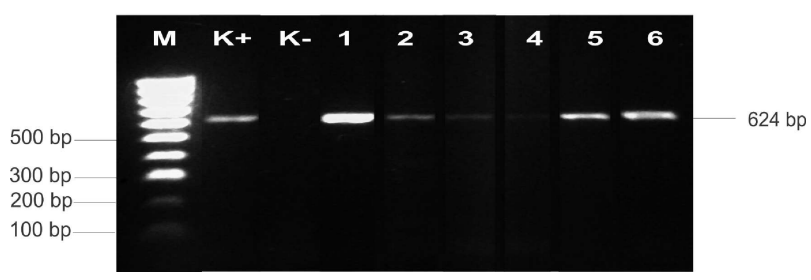

FIGURE 1 Electrophoresis photo of positive samples of unpurified PCR products on 1.5\% agarose gel using DNA-ladder $100 \mathrm{bp}$. M) Marker $\mathrm{K}+$ ) Positive controls, K-) Negative controls, samples 1) $\mathrm{KHJ} / \mathrm{C} 2$, 2) $\mathrm{KHJ} / \mathrm{A} 2$, 3) $\mathrm{KSK} / \mathrm{L}$, 4) $\mathrm{KHJ} / \mathrm{L}$, 5) $\mathrm{KNP} / \mathrm{M} 2$, and 6) $\mathrm{KHJ} / \mathrm{M} 2$.

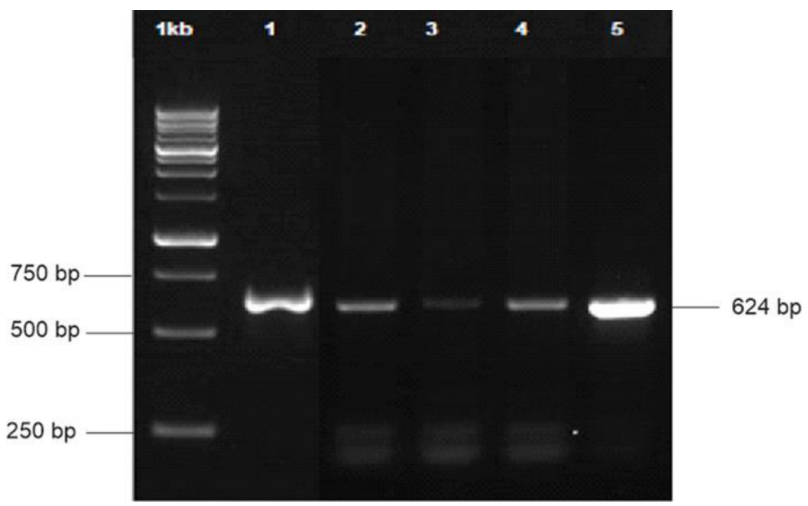

FIGURE 2 Electrophoresis of purified PCR products using DNAladder 250 bp. Samples: 1) KHJ/C2, 2) KHJ/A2, 3) KSK/L, 4) KHJ/L, and 5) KNP/M2. 
BLAST results from five samples on groEL gene forward primer Anaplasma spp. obtained the same maximum score and total score between 1059-1072 (high score). The value of the query cover is $97 \%$, which means that as much as $97 \%$ of the length of the sequenced nucleotide sequence can be compared with the database. The E-value of all samples was 0.0 . This indicates that the similarity between pairs was very convincing with $99 \%$ identity value.

TABLE 2 Data of PCR products from 51 dogs.

\begin{tabular}{|c|c|c|c|c|c|}
\hline No & Name & Age & Breed & Sex & PCR Result \\
\hline 1 & BLACKY KHJ/B & 6 years & Pug & Female & Negative \\
\hline 2 & DOM KD/D & 5 years & Pit Bull & Male & Negative \\
\hline 3 & HANI KHJ/H & 6 years & Local & Female & Negative \\
\hline 4 & ROXY KHJ/R & 9 months & Local & Female & Negative \\
\hline 5 & JOJO KHJ/J & 4 years & Shi-Tzu & Male & Negative \\
\hline 6 & AVRIL KHJ/A & 4 years & Siberian Husky & Female & Negative \\
\hline 7 & GIO KNP/G & 6 months & Kintamani & Male & Negative \\
\hline 8 & KORA KSK/K & - & Local & Male & Negative \\
\hline 9 & ASTRO KHJ/A2 & 3 years & Siberian Husky & Male & Positive Anaplasma spp. \\
\hline 10 & LALA KSK/L & - & Shi-Tzu & Female & Positive Anaplasma spp. \\
\hline 11 & AUDRY KNP/A & 1.4 years & Siberian Husky & Male & Negative \\
\hline 12 & LUPPY KSK/L2 & - & Siberian Husky & Male & Negative \\
\hline 13 & SUSU KHJ/S & 1 year & Local & Female & Negative \\
\hline 14 & $\mathrm{MOCHI} \mathrm{KHJ/M}$ & 15 years & Pug & Female & Negative \\
\hline 15 & LUNA KHJ/L & 2 years & Golden & Female & Positive Anaplasma spp. \\
\hline 16 & KENZO KHJ/K & 1 year & Local & Male & Negative \\
\hline 17 & VELLO KSK/V & 1.5 years & Red Poodle & Male & Negative \\
\hline 18 & SELLY PM/S & 1.5 years & Local & Male & Negative \\
\hline 19 & DIDOT KHJ/D & 3 months & Local & Male & Negative \\
\hline 20 & ALZHURA KHJ/A3 & 4 years & Local & Male & Negative \\
\hline 21 & BUFFY KHJ/B2 & - & Local & Male & Negative \\
\hline 22 & YOLO RSH/Y & 1 year & Local & Male & Negative \\
\hline 23 & CHIKITA RSH/C & 5 years & Local & Female & Negative \\
\hline 24 & NEXI KNP/N & 10 months & Local & Male & Negative \\
\hline 25 & KOPI KHJ/K2 & 1.4 years & Local & Male & Negative \\
\hline 26 & $\mathrm{CHOCHO} \mathrm{KHJ/C}$ & 3.5 years & Local & Male & Negative \\
\hline 27 & ELBY KHJ/E & 3.5 months & Pomeranian & Female & Negative \\
\hline 28 & KEYLA KHJ/K3 & - & Local & Female & Negative \\
\hline 29 & KOKO KHJ/K4 & 5 years & Local & Male & Negative \\
\hline 30 & $\mathrm{PICCO}$ RSH/P & 2.5 years & Local & Male & Negative \\
\hline 31 & NOKI KD/N & 1 year & Local & Female & Negative \\
\hline 32 & GOBEL KNP/G2 & 2 years & Beagle & Male & Negative \\
\hline 33 & MOI KNP/M & 1.3 years & Beagle & Male & Negative \\
\hline 34 & JACKO KHJ/J2 & 2 years & Siberian Husky & Male & Negative \\
\hline 35 & TANGO KD/T & 10 years & Local & Male & Negative \\
\hline 36 & $\mathrm{COCO} \mathrm{KHJ} / \mathrm{C} 2$ & - & Local & Male & Positive Anaplasma spp. \\
\hline 37 & CHERRY KHJ/C3 & 7 years & Local & Female & Negative \\
\hline 38 & MINION KNP/M2 & 7 month & Local Mix & Female & Positive Anaplasma spp. \\
\hline 39 & CHESTER KHJ/C4 & 7 years & Golden & Male & Negative \\
\hline 40 & POMPOM KHJ/P & 8 months & Pomeranian & Male & Negative \\
\hline 41 & YODA KNP/Y & - & Local & Male & Negative \\
\hline 42 & SWEETY KHJ/S2 & 13 years & Local & Female & Negative \\
\hline 43 & FLAFLA KHJ/F & 7 years & Local & Female & Negative \\
\hline 44 & NICK KHJ/N & - & Shi-Tzu & Female & Negative \\
\hline 45 & MOLI KHJ/M2 & 4 years & Local & Female & Positive Anaplasma spp. \\
\hline 46 & VON KHJ/V & 2 months & Local & Male & Negative \\
\hline 47 & MAYO RSH/M & 7 months & Local & Female & Negative \\
\hline 48 & JUSTIN KHJ/J3 & 10 years & Shi-Tzu & Male & Negative \\
\hline 49 & SAMMY KHJ/S3 & 10 years & Local & Male & Negative \\
\hline 50 & PONNY RSH/P2 & 2 years & Local & Female & Negative \\
\hline 51 & HEPPY RSH/H & - & Local & Female & Negative \\
\hline
\end{tabular}


The homology level of all samples shows very high homology by producing flat and parallel lines. The details of the data from the BLAST results can be seen in Table 3 .

Nucleotide differences between sample sequences and GenBank could be identifies using Molecular Evolutionary Genetics Analysis (MEGA) software version 7.0. Nucleotide differences were analyzed between Anaplasma spp. groEL gene sequences from five samples; A1 (KHJ/C2), A2 (KHJ/A2), A3 (KSK/L), A4 (KHJ/L), and A5 (KNP/M2) and groEL gene sequence data from GenBank; Anaplasma platys (AF478129.1), Anaplasma phagocytophilum (KU519286.1), Ehrlichia canis (U96731.1), Wolbachia endosymbiont (EF468716.1), and Neorickettsia sp (Table 4).

The results of the analysis obtained the difference value between $0-198$. A value of 0 states that there is no nucleotide difference, which means that there are genotypic similarities as shown between five samples (A1-A5) and Anaplasma platys (AF478129.1). Considerable values of genotypic differences are shown in Anaplasma phagocytophilum (KU519286.1), Ehrlichia canis (U96731.1), Wolbachia endosymbiont (EF468716.1), and Neorickettsia sp. (AY050314.1), with 105, 136, 151, and 198 nucleotides, respectively. The smaller nucleotide difference values indicate closer kinship because it is getting closer to genetic similarity.

Genetic distance is a genetic difference between species or between populations in one species. A small genetic distance or close to 0 value indicates a close ge- netic relationship, while a large genetic distance or close to a value of 1 indicates a distant genetic relationship. Genetic distance can be analyzed by using Molecular Evolutionary Genetics Analysis (MEGA) software version 7.0. Results of genetic distance analysis between sequences of groEL gene Anaplasma spp. from five samples; A1 (KHJ/C2), A2 (KHJ/A2), A3 (KSK/L), A4 (KHJ/L), and A5 (KNP/M2) with sequence data of the A. platys groEL gene from GenBank obtained a value of $0 \%$. These results indicate that the five study samples had $100 \%$ homology with A. platys (AF478129.1) from GenBank, which suggests that there is no genetic diversity in A. platys infecting dogs in Yogyakarta, Indonesia. Data from the analysis are shown in Table 5.

Other analysis results showed 21\% genetic distance with A. phagocytophilum (KU519286.1), 27\% genetic distance with E. canis (U96731.1), 30\% genetic distance with W. endosymbiont (EF468716.1), and 40\% genetic distance with Neorickettsia sp. (AY050314.1). Homology values are $79 \%, 73 \%, 70 \%$, and $60 \%$, respectively. Genetic distance between five samples with Neorickettsia sp. (AY050314.1) is the furthest genetic distance.

\subsection{Phylogenetic analysis}

The phylogenetic tree was constructed using the NeighborJoining method using Molecular Evolutionary Genetics Analysis (MEGA) software version 7.0 (Kumar et al. 2016). Phylogenetic tree construction between groEL gene sequences of Anaplasma spp. from five samples;

TABLE 3 The results of data analysis using BLAST.

\begin{tabular}{|c|c|c|c|c|c|c|}
\hline Sample Code & GenBank & Max score and total score & Query cover & E-value & Identity & Access Code \\
\hline $\mathrm{KHJ} / \mathrm{C} 2$ & Anaplasma platys & 1064 & $97 \%$ & 0.0 & $99 \%$ & AF478129.1 \\
\hline $\mathrm{KHJ} / \mathrm{A} 2$ & Anaplasma platys & 1062 & $97 \%$ & 0.0 & $99 \%$ & AF478129.1 \\
\hline $\mathrm{KSK} / \mathrm{L}$ & Anaplasma platys & 1059 & $97 \%$ & 0.0 & $99 \%$ & AF478129.1 \\
\hline $\mathrm{KHJ} / \mathrm{L}$ & Anaplasma platys & 1072 & $97 \%$ & 0.0 & $99 \%$ & AF478129.1 \\
\hline KNP/M2 & Anaplasma platys & 1062 & $97 \%$ & 0.0 & $99 \%$ & AF478129.1 \\
\hline
\end{tabular}

TABLE 4 Matrix of differences between sequence of groEL nucleotide of Anaplasma spp. from research samples and sequences from GenBank in several species.

\begin{tabular}{|c|c|c|c|c|c|c|c|c|c|c|}
\hline No & Sample & 1 & 2 & 3 & 4 & 5 & 6 & 7 & 8 & 9 \\
\hline 1 & AF478129.1_Anaplasma platys & & & & & & & & & \\
\hline 2 & $\mathrm{~A} 1(\mathrm{KHJ} / \mathrm{C} 2)$ & 0 & & & & & & & & \\
\hline 3 & $\mathrm{~A} 2(\mathrm{KHJ} / \mathrm{A} 2)$ & 0 & 0 & & & & & & & \\
\hline 4 & A3 (KSK/L) & 0 & 0 & 0 & & & & & & \\
\hline 5 & $\mathrm{~A} 4(\mathrm{KHJ} / \mathrm{L})$ & 0 & 0 & 0 & 0 & & & & & \\
\hline 6 & A5 (KNP/M2) & 0 & 0 & 0 & 0 & 0 & & & & \\
\hline 7 & KU519286.1_Anaplasma phagocytophilum & 105 & 105 & 105 & 105 & 105 & 105 & & & \\
\hline 8 & U96731.1_Ehrlichia canis & 136 & 136 & 136 & 136 & 136 & 136 & 127 & & \\
\hline 9 & EF468716.1_Wolbachia endosymbiont & 151 & 151 & 151 & 151 & 151 & 151 & 149 & 130 & \\
\hline 10 & AY050314.1_Neorickettsia sp. & 198 & 198 & 198 & 198 & 198 & 198 & 193 & 178 & 188 \\
\hline
\end{tabular}


TABLE 5 Genetic distance of groEL sequences of Anaplasma spp. from research samples with sequences from GenBank in several species.

\begin{tabular}{|c|c|c|c|c|c|c|c|c|c|c|}
\hline No & Sample & 1 & 2 & 3 & 4 & 5 & 6 & 7 & 8 & 9 \\
\hline 1 & AF478129.1_Anaplasma platys & & & & & & & & & \\
\hline 2 & $\mathrm{~A} 1(\mathrm{KHJ} / \mathrm{C} 2)$ & 0.00 & & & & & & & & \\
\hline 3 & $\mathrm{~A} 2(\mathrm{KHJ} / \mathrm{A} 2)$ & 0.00 & 0.00 & & & & & & & \\
\hline 4 & $\mathrm{~A} 3(\mathrm{KSK} / \mathrm{L})$ & 0.00 & 0.00 & 0.00 & & & & & & \\
\hline 5 & $\mathrm{~A} 4(\mathrm{KHJ} / \mathrm{L})$ & 0.00 & 0.00 & 0.00 & 0.00 & & & & & \\
\hline 6 & A5 (KNP/M2) & 0.00 & 0.00 & 0.00 & 0.00 & 0.00 & & & & \\
\hline 7 & KU519286.1_Anaplasma phagocytophilum & 0.21 & 0.21 & 0.21 & 0.21 & 0.21 & 0.21 & & & \\
\hline 8 & U96731.1_Ehrlichia canis & 0.27 & 0.27 & 0.27 & 0.27 & 0.27 & 0.27 & 0.25 & & \\
\hline 9 & EF468716.1_Wolbachia endosymbiont & 0.30 & 0.30 & 0.30 & 0.30 & 0.30 & 0.30 & 0.30 & 0.26 & \\
\hline 10 & AY050314.1_Neorickettsia sp. & 0.40 & 0.40 & 0.40 & 0.40 & 0.40 & 0.40 & 0.39 & 0.36 & 0.38 \\
\hline
\end{tabular}

A1 (KHJ/C2), A2 (KHJ/A2), A3 (KSK/L), A4 (KHJ/L), and A5 (KNP/M2) with groEL gene sequence data from GenBank: A. platys (AF478129.1), A. phagocytophilum (KU519286.1), E. canis (U96731.1), W. endosymbiont (EF468716.1), and Neorickettsia sp. (AY050314.1) was conducted based on the conclusion of 1,000 times repetition bootstrapping and adjustment of genetic distance with the parameters of the Kimura-2 nucleotide substitution model. The results of the construction in the study can be seen in Figure 3.

The results of the phylogenetic tree construction showed a formation of five main clades: clade I was occupied by Neorickettsia sp. (AY050314.1), clade II W. endosymbiont(EF468716.1), clade III E. canis (U96731.1), clade IV A. phagocytophilum (KU519286.1). Sequences of study samples A1 (KHJ/C2), A2 (KHJ/A2), A3 (KSK/L), A4 (KHJ/L), and A5 (KNP/M2) belonged to the same clade with A. platys (AF478129.1) which is at clade

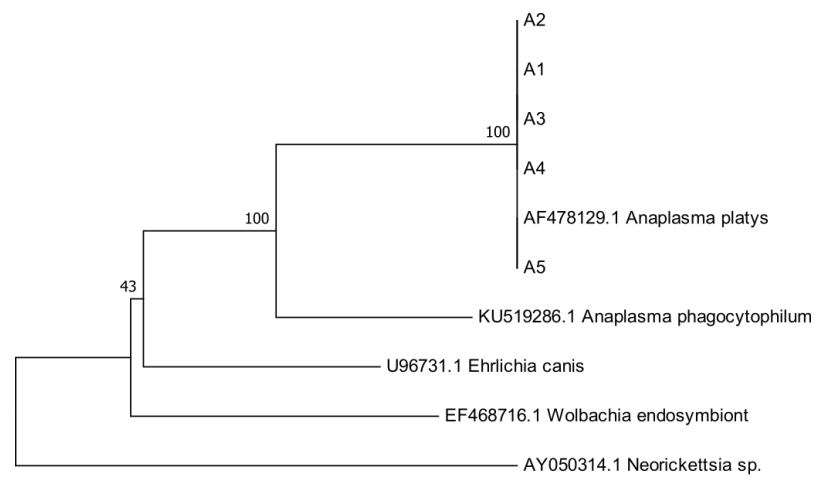

$\longmapsto 0.050$

FIGURE 3 Construction of phylogenetic tree; based on the conclusion by 1,000 times repetition bootstrapping and adjustment of genetic distance with the Kimura-2 nucleotide substitution model parameters using the MEGA version 7.0 application, compared to the groEL gene sequence of Anaplasma platys (AF478129.1), Anaplasma phagocytophilum (KU519286.1), Ehrlichia canis (U96731.1), Wolbachia endosymbiont (EF468716.1), and $\mathrm{Ne}$ orickettsia sp. (AY050314.1) from GenBank; A1) KHJ/C2, A2) $\mathrm{KHJ} / \mathrm{A} 2, \mathrm{~A} 3) \mathrm{KSK} / \mathrm{L}, \mathrm{A} 4) \mathrm{KHJ} / \mathrm{L}$, and A5) KNP/M2.
V. Sequences which belongs to the same clade show the closest kinship, while kinship distance is calculated by genetic distance scale (horizontal calculation). The analysis obtained a kinship distance scale of 0.05 each length in the image. Based on the conclusions by 1,000 repetitions bootstrapping, it was found that the consistency of clade formation was $100 \%$ in clades IV and V (Figure 3). Study samples A1 (KHJ/C2), A2 (KHJ/A2), A3 (KSK/L), A4 (KHJ/L), and A5 (KNP/M2) have a close kinship with $A$. platys (AF478129.1) from Democratic Republic of Congo (DRC), Africa. These results indicate that A. platys infecting dogs in Yogyakarta, Indonesia, does not have genetic diversity and is a distant relative of A. phagocytophilum (KU519286.1), E. canis (U96731.1), W. endosymbiont (EF468716.1), and Neorickettsia sp. (AY050314.1).

\section{Discussion}

The GroEL protein is a part of the heat shock protein-group (HSP), and is also called eukaryotic HSP60 (based on its molecular weight of $60 \mathrm{kDa}$ ). Heat shock proteins are regulated in physiological stressful situations, for example during an increase in temperature or toxicity, therefore this protein serves as a cell protection tool. The groEL gene is one product of two genes (groEL ["L" means large] and groES ["S" means small]) that is united in the groESL gene. The sequence of genes is considered a useful tool for phylogenetic analysis of Anaplasma spp., especially in cases where analysis of 16S rRNA is limited due to high conservation, groEL genes can support and expand phylogenetic results (Dasch et al. 1990; Jahfari et al. 2014). Characterization based on groEL gene targets in diagnosing $A$. platys has been carried out in various countries such as the Philippines (Ybañez et al. 2012)), Taiwan (Yuasa et al. 2017), Italy (Fuente et al. 2006), and Venezuela (Huang et al. 2005).

According to Inokuma et al. (2002), the sequence determination of N Heat Shock Operon ( $g r o E S L$ ) genes and Citrate Synthase Gene (gltA) from A. platys for phylogenetic and diagnostic studies give results that groESL and gltA genes both have a greater variety of gene sequences 
compared to the 16S rRNA gene sequence. The specificity of these genes was examined using the DNA of three A. platys strains from different geographical locationsFrance, Japan, and Venezuela — and using DNA from nearby species, including $A$. phagocytophilum and $A$. marginale. The results showed that both PCR systems of groESL and gltA genes are specific to A. platys. The latest study in the Philippines by (Ybañez et al. 2016) regarding the phylogenetic analysis of A. platys using the groEL gene target reported that $A$. platys co-infection of different variants has been reported. This was not found in phylogenetic analysis using the $16 \mathrm{~S}$ gene target in the same study and had not even been explained in previous studies.

The phylogenetic analysis showed a close relationship between A. platys in Yogyakarta and A. platys from the Democratic Republic of Congo (DRC) in Africa. This indicated that there was a possibility that $A$. platys species from the African region can spread to Indonesia through the activity of importing animal trade or tourists entering to Indonesian territory if it was associated with the condition and clinical symptom of animals infected with $A$. platys tend to be asymptomatic (Sykes and Foley 2013).

\section{Conclusions}

The incidence of anaplasmosis in dog patients in Yogyakarta and its surrounding areas was confirmed based on molecular diagnosis using the PCR technique with the groEL gene target. Study samples A1 (KHJ/C2), A2 (KHJ/A2), A3 (KSK/L), A4 (KHJ/L), and A5 (KNP/M2) have a close kinship with Anaplasma platys (AF478129.1) from the Democratic Republic of Congo (DRC) in Africa. The results of a phylogenetic analysis show very high homology values (100\%) with a bootstrap value of $100 \%$. This shows that there is no genetic diversity in A. platys that infected dogs in the Yogyakarta area.

\section{Acknowledgments}

The authors would like to express their gratitude to 2018 Faculty Competitive Research Faculty of Veterinary Medicine, Universitas Gadjah Mada, No. 1584/J01.1.22/HK4/2018. Gratitude also goes to all parties who have helped to complete the research, especially to the laboratory staff at the Laboratory of the Department of Internal Medicine and the Department of Biochemistry, Faculty of Veterinary Medicine, Universitas Gadjah Mada.

\section{Authors' contributions}

MDF, AH, IT, designed the study. MDF carried out the laboratory work. MDF, AH, IT analyzed the data. MDsF wrote the manuscript. All authors read and approved the final version of the manuscript.

\section{Competing interests}

The authors declare no competing interests.

\section{References}

Alberti A, Zobba R, Chessa B, Addis MF, Sparagano O, Parpaglia MLP, Cubeddu T, Pintori G, Pittau M. 2005. Equine and canine Anaplasma phagocytophilum strains isolated on the Island of Sardinia (Italy) are phylogenetically related to pathogenic strains from the United States. Appl Environ Microbiol. 71(10):6418-6422. doi:10.1128/aem.71.10. 6418-6422.2005.

Aprilyanto V, Sembiring L. 2016. Filogenetik molekuler. Yogyakarta: Innosain.

Arraga-Alvarado CM, Qurollo BA, Parra OC, Berrueta MA, Hegarty BC, Breitschwerdt EB. 2014. Molecular evidence of Anaplasma platys infection in two women from Venezuela. Am J Trop Med Hyg. 91(6):11611165. doi:10.4269/ajtmh.14-0372.

Beaufils JP, Inokuma H, Martin-Granel J, Jumelle P, Barbault-Jumelle M, Brouqui P. 2002. Anaplasma platys (Ehrlichia platys) infection in a dog in France: description of the case, and characterization of the agent. Revue Med Vet. 153(2):85-90.

Bonilla MC, Campos-Calderon L, Jemenez-Rocha AE, Romero-Zuniga JJ, Alberti A, Zobba R, Dolz G. 2017. Characterization of Anaplasma spp. infection in dogs from Costa Rica. Vet Parasitol Reg Stud Rep. 8:60-65. doi:10.1016/j.vprsr.2017.02.003.

Carrade DD, Foley JE, Borjesson DL. 2009. Canine granulocytic anaplasmosis: A review. J Vet Intern Med. 23(6):1129-1141. doi:10.1111/j.1939-1676. 2009.0384.x.

Dasch GA, Ching WM, Kim PY, Pham H, Stover CK, Oaks EV, Dobson ME, Weiss E. 1990. A structural and immunological comparison of rickettsial HSP60 antigens with those of other species. Ann N Y Acad Sci. 590(1):352-369. doi:10.1111/j.1749-6632.1990. tb42242.x.

de Farias Rotondano TE, de Almeida AMP, Lustosa EMC, Cordeiro AA, Camboim EKA, de Azevedo SS, de Andrade PP, de Melo MA. 2012. An assessment of whole blood and fractions by nested PCR as a DNA source for diagnosing canine ehrlichiosis and anaplasmosis. Sci World J. 2012:1-6. doi:10.1100/2012/605743.

Dyachenko V, Pantchev N, Balzer HJ, Meyersen A, Straubinger RK. 2012. First case of Anaplasma platys infection in a dog from Croatia. Parasites Vectors. 5(49):1-7. doi:10.1186/1756-3305-5-49.

Fuente J, Torina A, Naranjo V, Nicosia S, Alongi A, Mantia FL, Kocan KM. 2006. Molecular characterization of Anaplasma platys strains from dogs in Sicily, Italy. BMC Vet Res. 2(24):1-5. doi:10.1186/ 1746-6148-2-24.

Gaunt SD, Baker DC, Babin SS. 1990. Platelet aggregation studies in dogs with acute Ehrlichia platys infection. Am J Vet Res. 51(2):290-293.

Greene CE. 2012. Infectious diseases of the dog and cat. $4^{\text {th }}$ edition. Saunders: Elsevier Health Sciences.

Hadi UK, Soviana S, Pratomo IRC. 2016. Prevalence of ticks and tick-borne diseases in Indonesian dogs. J 
Vet Sci Technol. 7(3):1-7. doi:10.4172/2157-7579. 1000330.

Harrus S, Aroch I, Lavy E, Bark H. 1997. Clinical manifestations of infectious canine cyclic thrombocytopenia. Vet Rec. 141(10):247-250. doi:10.1136/vr.141. 10.247.

Huang H, Unver A, Perez MJ, Orellana NG, Rikihisa Y. 2005. Prevalence and molecular analysis of Anaplasma platys in dogs in Lara, Venezuela. Braz J Microbiol. 36(3):211-216. doi:10.1590/ s1517-83822005000300002.

Inokuma $\mathrm{H}$, Fujii K, Okuda M, Onishi T, Beaufils JP, Raoult D, Brouqui P. 2002. Determination of the nucleotide sequences of heat shock operon groESL and the citrate synthase gene ( $g l t A$ ) of Anaplasma (Ehrlichia) platys for phylogenetic and diagnostic studies. Clin Diagn Lab Immunol. 9(5):1132-1136. doi:10.1128/cdli.9.5.1132-1136.2002.

Jahfari S, Coipan E, Fonville M, van Leeuwen A, Hengeveld P, Heylen D, Heyman P, van Maanen C, Butler CM, Földvári G, et al. 2014. Circulation of four Anaplasma phagocytophilum ecotypes in Europe. Parasites Vectors. 7(365):1-11. doi:10.1186/ 1756-3305-7-365.

Kelly WR. 1984. Veterinary clinical diagnosis. $3^{\text {rd }}$ edition. London: Bailliere Tindall.

Kontos VI, Papadopoulos O, French TW. 1991. Natural and experimental canine infections with a Greek strain of Ehrlichia platys. Vet Clin Pathol. 20(4):101-105. doi:10.1111/j.1939-165x.1991.tb00867.x.

Kumar S, Stecher G, Tamura K. 2016. MEGA7: molecular evolutionary genetics analysis version 7.0 for bigger datasets. Mol Biol Evol. 33(7):1870-1874. doi: 10.1093/molbev/msw054.

Lee SH, Kim N, Kwak D. 2017. First clinical case of canine granulocytic anaplasmosis in Korea and genotypic analyses of Anaplasma phagocytophilum. Ticks Tick Borne Dis. 8(4):462-465. doi:10.1016/j.ttbdis. 2017.02.003.

Lillini E, Macrì G, Proietti G, Scarpulla M. 2006. New findings on anaplasmosis caused by infection with Anaplasma phagocytophilum. Ann N Y Acad Sci. 1081(1):360-370. doi:10.1196/annals.1373.053.

Matei IA, D’Amico G, Yao PK, Ionică AM, Kanyari PWN, Daskalaki AA, Dumitrache MO, Sándor AD, Gherman CM, Qablan M, et al. 2016. Molecular detection of Anaplasma platys infection in free-roaming dogs and ticks from Kenya and Ivory Coast. Parasites Vec- tors. 9(157):1-8. doi:10.1186/s13071-016-1443-3.

Otranto D, Testini G, Dantas-Torres F, Latrofa MS, d P Diniz PPV, de Caprariis D, Lia RP, Mencke N, Stanneck D, Capelli G, Breitschwerdt EB. 2010. Diagnosis of canine vector-borne diseases in young dogs: a longitudinal study. J Clin Microbiol. 48(9):3316-3324. doi:10.1128/jcm.00379-10.

Ribeiro CM, Matos AC, Azzolini T, Bones ER, Wasnieski EA, Richini-Pereira VB, Lucheis SB, Vidotto O. 2017. Molecular epidemiology of Anaplasma platys, Ehrlichia canis and Babesia vogeli in stray dogs in Paraná, Brazil. Pesqui Vet Bras. 37(2):129-136. doi: 10.1590/s0100-736x2017000200006.

Santos AS, Alexandre N, Sousa R, Nuncio MS, Bacellar F, Dumler JS. 2009. Serological and molecular survey of Anaplasma species infection in dogs with suspected tickborne disease in Portugal. Vet Rec. 164(6):168171. doi:10.1136/vr.164.6.168.

Sykes JE, Foley JE. 2013. Canine and feline infectious diseases. Philadelphia: Elsevier Health Sciences.

Vargas-Hernandez G, André MR, Cendales DM, de Sousa KCM, Gonçalves LR, Rondelli MCH, Machado RZ, Tinucci-Costa M. 2016. Molecular detection of anaplasma species in dogs in Colombia. Rev Bras Parasitol Vet. 25(4):459-464. doi:10.1590/ s1984-29612016066.

Ybañez AP, Perez ZO, Gabotero SR, Yandug RT, Kotaro M, Inokuma H. 2012. First molecular detection of Ehrlichia canis and Anaplasma platys in ticks from dogs in Cebu, Philippines. Ticks Tick Borne Dis. 3(56):288-293. doi:10.1016/j.ttbdis.2012.10.032.

Ybañez AP, Ybañez RHD, Yokoyama N, Inokuma H. 2016. Multiple infections of Anaplasma platys variants in Philippine dogs. Vet World. 9(12):1456-1460. doi:10.14202/vetworld.2016.1456-1460.

Yu XJ, Zhang VF, McBride JW, Zhang Y, Walker DH. 2001. Phylogenetic relationship of Anaplasma marginale and Ehrlichia platys to other Ehrlichia species determined by groEL amino acid sequences. Int J Syst Evol Microbiol. 51(3):1143-1146. doi:10. 1099/00207713-51-3-1143.

Yuasa Y, Tsai Y, Chang C, Hsu T, Chou C. 2017. The prevalence of Anaplasma platys and a potential novel Anaplasma species exceed that of Ehrlichia canis in asymptomatic dogs and Rhipicephalus sanguineus in Taiwan. J Vet Med Sci. 79(9):1494-1502. doi:10. 1292/jvms.17-0224. 